\title{
Panophthalmitis with orbital cellulitis following glaucoma drainage implant surgery in a pediatric patient
}

\author{
Panoftalmite com celulite orbitária após implante de drenagem em glaucoma congênito
}

Bruno L. B. Esporcatte ${ }^{1}$, Luiz Fernando Teixeira ${ }^{1}$, Christiane Rolim-de-Moura ${ }^{1}$

\begin{abstract}
Here we report a case of childhood glaucoma refractory to angle and trabeculectomy surgery. The patient was treated with an Ahmed ${ }^{\mathrm{TM}}$ drainage implant that was subsequently complicated by rapid-onset panophthalmitis and orbital cellulitis Intravenous and intravitreal antibiotic therapy was initiated and the drainage tube was removed. The infectious process resolved within 3 weeks; however, phthisis bulbi developed subsequently.
\end{abstract}

Keywords: Glaucoma/congenital; Glaucoma drainage implant; Endophthalmitis/ surgery; Panophthalmitis/surgery; Orbital cellulitis

\section{RESUMO}

Relato de um caso de uma criança portadora de glaucoma congênito primário, refratário a cirurgias angulares e trabeculectomias prévias, submetido à implante de drenagem do tipo Ahmed ${ }^{\circledR}$. O paciente evoluiu com panoftalmite e celulite orbitária de aparecimento súbito, sendo submetido à remoção do tubo e antibioticoterapia endovenosa e intravítrea. O processo infeccioso foi resolvido em três semanas, porém o olho evoluiu para phthisis bulbi.

Descritores: Glaucoma/congênito; Implantes para drenagem de glaucoma; Endoftalmite/cirurgia; Panoftalmite/cirurgia; Celulite orbitária

\section{INTRODUCTION}

Primary congenital glaucoma (PCG) is the most frequent childhood glaucoma and an important cause of blindness. Surgical management of PCG is challenging because of an elevated risk of complications and failure of surgery as a result of anatomical factors related to ocular enlargement and aggressive healing ${ }^{(1)}$.

Goniotomy and trabeculotomy are the first-line surgical interventions for PCG; however, approximately 15\%-20\% of PCG cases are refractory to these techniques ${ }^{(2)}$. When angle procedures fail, more invasive surgeries are required to reduce the intraocular pressure (IOP), such as trabeculectomy or insertion of a glaucoma drainage implant ${ }^{(3)}$.

Here we present an atypical case of panophthalmitis with orbital cellulitis following treatment with an Ahmed ${ }^{\mathrm{TM}}$ glaucoma valve (AGV) implant.

\section{CASE REPORT}

The patient was a 15-month-old male child who presented to the ophthalmologic emergency room of Hospital São Paulo with severe edema and erythema affecting the superior eyelid of the left eye. The mother had observed moderate hyperemia and purulent eye discharge associated with prostration and low fever over a period of 2 days previously. Examination was limited due to a lack of cooperation. Routine ophthalmological evaluation performed a week earlier had been unremarkable.

According to the parents, the patient had a history of blepharospasm, epiphora, and photophobia in both eyes since birth and had been diagnosed with PCG at 2 months of age. All information related to previous ophthalmological history was collected from medical re- cords (Pediatric Glaucoma Nucleus - Federal University of São Paulo). Initial examination under anesthesia revealed buphthalmos [axial length: $22.43 \mathrm{~mm}$, oculus dexter (OD); $23.99 \mathrm{~mm}$, oculus sinister (OS)], corneal enlargement [13 mm, oculus uterque (OU)] with important haze and an elevated IOP (OD: 24 mmHg/OS: 28 mmHg). Trabeculotomy was subsequently performed on both eyes.

In order to manage IOP during the first year, other surgeries were attempted on both eyes, including trabeculotomy (OS), combined trabeculotomy and trabeculectomy (OD), and trabeculectomy (OU). All surgeries were uneventful.

One month prior to this presentation to the emergency room, the patient presented with bilateral increases in axial length $(O D$, $28.60 \mathrm{~mm}$; OS, $28.76 \mathrm{~mm}$ ) and an elevated IOP. No filtration bleb was observed in the OS during ophthalmological examination under anesthesia. Subsequently, uneventful AGV implantation was performed (FP7 model, New World Medical Inc., Rancho Cucamonga, CA). The parents stated that moxifloxacin $0.5 \%$ (4 times/day for 10 days) and prednisolone acetate 1\% (5 times/day for 4 weeks) had been adequately instilled in the OS during the postoperative period.

Prompt hospitalization was recommended in light of the initial pediatric examination. Blood samples were collected for culture and empirical intravenous antibiotic treatment with vancomycin $(60 \mathrm{mg} / \mathrm{kg} /$ day) and cefepime (150 mg/kg/day) was initiated. Computed tomography of the orbit and ocular ultrasonography were performed.

Computed tomography suggested infiltration of the periorbitary tissue, generalized scleral thickening, and increased density of the postseptal fat (Figure 1). Ultrasonography findings included low-amplitude mobile echoes, vitreous membranes, and thickening of the retina and choroid (Figure 2) 


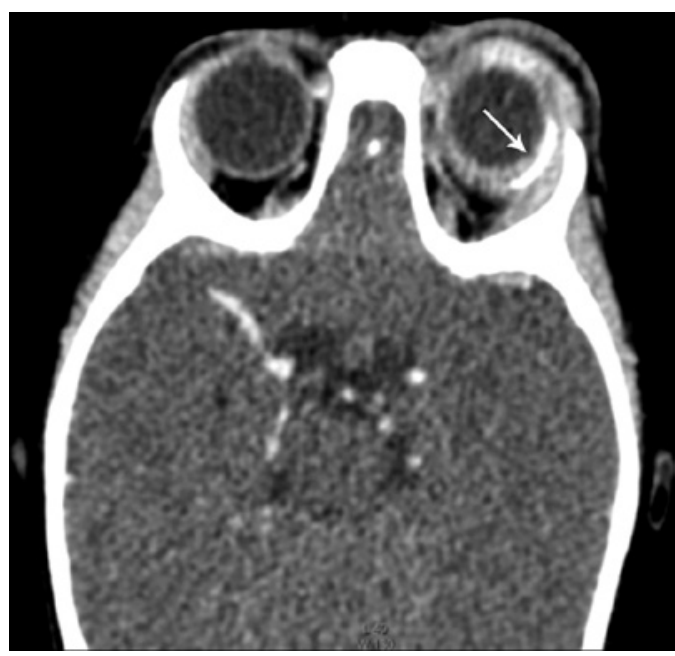

Figure 1. Orbital computed tomography demonstrated proptosis, inflammation of the extraconal fat, scleral thickening, and diffuse purulent collection surrounding the $\mathrm{Ahmed}^{\mathrm{TM}}$ glaucoma valve implant (arrow).

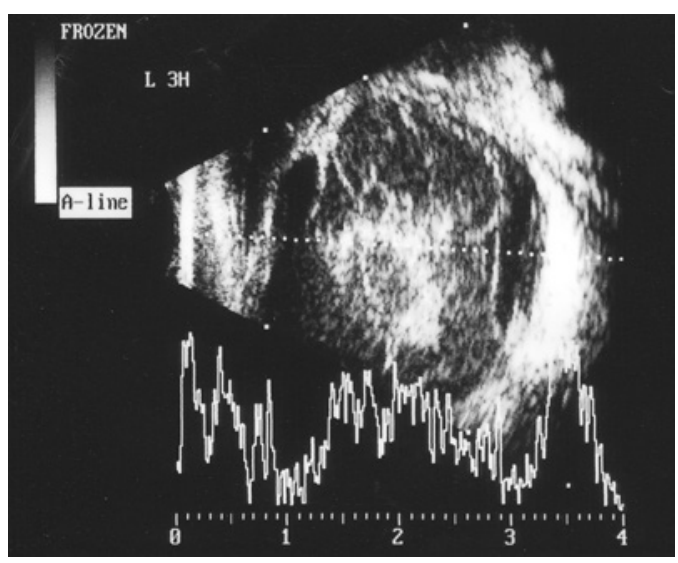

Figure 2. B-scan ultrasonography demonstrated vitreous opacities.

The patient was examined under anesthesia on the same day. Perioperative observations revealed a swollen, tense, and hyperemic superior eyelid. The OS was proptotic. The conjunctiva was chemotic and had significant hyperemia (3+/4), the cornea was diffusely hazy, and the anterior chamber had a large hypopyon. Neither the lens nor the ocular fundus could be visualized.

The previous surgical site was explored. Purulent material surrounding the valve was observed. The plate was removed and sent for bacterial culture analysis. Abundant irrigation with balanced saline solution was performed. A 30-gauge needle was introduced through the pars plana and a $0.3-\mathrm{ml}$ specimen was obtained from the vitreous and used to directly inoculate culture media. Vancomycin $(2.5 \mathrm{mg} / 0.1 \mathrm{ml})$ and ceftazidime $(2.5 \mathrm{mg} / 0.1 \mathrm{ml})$ were injected intravitreally and into the subtenon space.

Although repeated cultures from blood and vitreous samples were negative, cultures from the removed tube revealed infection with Staphylococcus epidermidis sensitive to amikacin, cefalotin, linezolid, rifampicin, and vancomycin.

The patient completed 8 days of treatment with intravenous vancomycin and cefepime during the hospital stay, topical gatifloxacin 5 times/day for 2 weeks, and 10 days of treatment with oral amoxicilin/ clavulanate potassium at home. Complete regression of eyelid edema was observed after 15 days of treatment (Figure 3). Unfortunately, the OS subsequently progressed to phthisis bulbi.
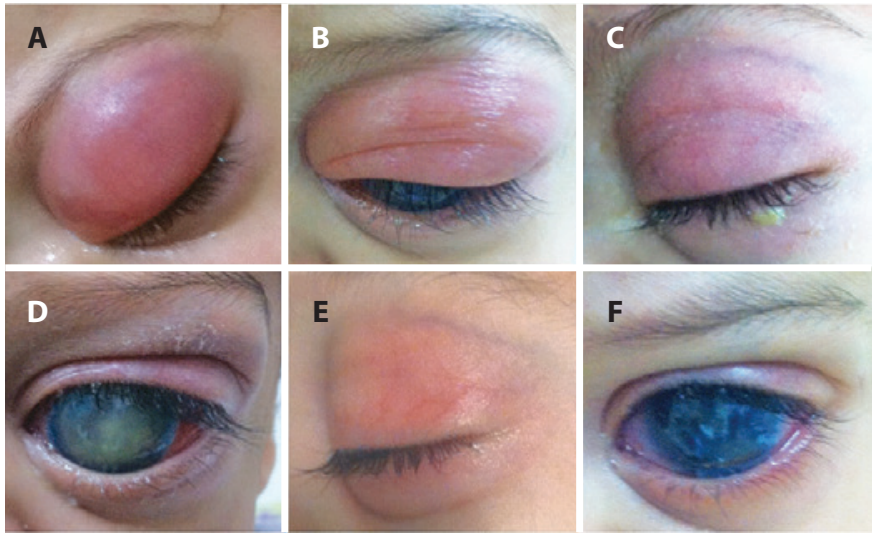

Figure 3. Clinical progression after glaucoma drainage device removal and antibiotic therapy, showing the regression of the eyelid edema. A) At presentation. B) One day postoperatively. C and D) Two days postoperatively. E) Seven days postoperatively. F) Fifteen days postoperatively.

\section{DISCUSSION}

Satisfactory success rates with the AGV to control IOP in pediatric glaucoma have been reported ${ }^{(3)}$. Infectious events in patients treated with glaucoma drainage implants are rare. In 2 long-term studies comparing outcomes following the use of Ahmed ${ }^{\mathrm{TM}}$ and Baerveldt $\mathrm{t}^{\mathrm{TM}}$ glaucoma devices, the incidence of endophthalmitis in adult patients was $0.8 \%$ and $2 \%$, respectively, with no significant difference observed between implants ${ }^{(4,5)}$.

There have been few reports describing similar complications in childhood glaucoma. A retrospective review of patients treated with AGVs by Al-Torbak et al. reported endophthalmitis in $4.4 \%$ of children (5/113 eyes) and $0.9 \%$ (4/429 eyes) of adults ${ }^{(6)}$. The time course for the development of endophthalmitis ranged from 4 weeks to 12 months, with a median time of 7 months postoperatively ${ }^{(7)}$.

Lack of compliance with postoperative care recommendations, including the avoidance of eye rubbing and non-adherence to topical treatments, may increase the risk of early infection in children. Generally, incisions heal insufficiently during the first postoperative month and conjunctival dehiscence allows ocular infiltration of bacterial agents through the ocular surface ${ }^{(8)}$.

The most frequently isolated organisms in cases of endophthalmitis following the insertion of glaucoma drainage implants in children are Haemophilus influenzae, Streptococcus pneumoniae, or both. These organisms are components of the normal bacterial flora of the conjunctiva and upper respiratory tract ${ }^{(8)}$. Orbital cellulitis in children is typically secondary to sinusitis, with Staphylococcus aureus and Streptococcus pyogenes isolated in $75 \%$ of $\operatorname{cases}^{(9)}$.

S. epidermidis is capable of forming biofilms, a characteristic of bacteria highly resistant to antibiotic treatment and found on the surface of prosthetic medical devices. The formation of biofilms has reportedly been observed on intraocular lenses, scleral buckles, corneal sutures, stents, and glaucoma tubes ${ }^{(10)}$.

Antibiotic regimens are typically initiated with broad-spectrum agents to cover gram-positive and gram-negative organisms known to cause postoperative endophthalmitis. In a retrospective study, Miller et al. demonstrated that $100 \%$ of the S. epidermidis strains isolated from vitreous samples were sensitive to vancomycin and 68\% were sensitive to fourth-generation fluoroquinolones ${ }^{(11)}$.

The recommendation of removing glaucoma shunt devices from eyes with endophthalmitis is controversial(6,12). In the present case, we decided to remove the AGV due to the presence of purulent material surrounding the plate. The prognosis of endophthalmitis ranges from recovery to previous visual acuity to progression to phthisis bulbi. 
Severe infections, such as orbital cellulitis, in pediatric cases require prompt hospitalization and initiation of intravenous antibiotic treatment because of the risk of posterior spread into the cavernous sinus. Parents should be informed of all surgical risks, complications, and warning signs to allow for early evaluation. Postoperative infectious events with prosthetic materials should be communicated to hospital infection committees and device manufacturers.

\section{REFERENCES}

1. Ou Y, Caprioli J. Surgical management of pediatric glaucoma. Dev Ophthalmol. 2012; 50:157-72.

2. Tanimoto SA, Brandt JD. Options in pediatric glaucoma after angle surgery has failed. Curr Opin Opthalmol. 2006;17(2):132-7.

3. Morad Y, Donaldson CE, Kim YM, Abdolell M, Levin AV. The Ahmed drainage implant in the treatment of pediatric glaucoma. Am J Ophthalmol. 2003:135(6):821-9.

4. Christakis PG, Tsai JC, Kalenak JW, Zurakowski D, Cantor LB, Kammer JA, Ahmed II. The Ahmed versus Baerveldt study: three-year treatment outcomes. Ophthalmology. 2013:120(11):2232-40.

5. Barton K, Feuer WJ, Budenz DL, Schiffman J, Costa VP, Godfrey DG, Buys YM; Ahmed
Baerveldt Comparison Study Group. Three-year treatment outcomes in the Ahmed Baerveldt comparison study. Ophthalmology. 2014;121(8):1547-57

6. Al-Torbak AA, Al-Shahwan S, Al-Jadaan I, Al-Hommadi A, Edward DP. Endophthalmitis associated with the Ahmed glaucoma valve implant. Br J Ophthalmol. 2005;89(4):454-8.

7. Wentzloff JN, Grosskreutz CL, Pasquale LR, Walton DS, Chen TC. Endophthalmitis after glaucoma drainage implant surgery. Int Ophthalmol Clin. 2007;47(2):109-15.

8. Gedde SJ, Scott IU, Tabandeh H, Luu KK, Budenz DL, Greenfield DS, Flynn HW Jr. Late endophthalmitis associated with glaucoma drainage implants. Ophthalmology. 2001; 108(7):1323-7.

9. Botting AM, Mclntosh D, Mahadevan M. Paediatric pre- and post-septal peri-orbital infections are different diseases. A retrospective review of 262 cases. Int J Pediatr Otorhinolaryngol. 2008:72(3):377-83.

10. Hou W, Sun X, Wang Z, Zhang Y. Biofilm-forming capacity of Staphylococcus epidermidis, Staphylococcus aureus, and Pseudomonas aeruginosa from ocular infections. Invest Ophthalmol Vis Sci. 2012:53(9):5624-31.

11. Miller DM, Vedula AS, Flynn HW Jr, Miller D, Scott IU, Smiddy WE, Murray TG, Venkatraman AS. Endophthalmitis caused by Staphylococcus epidermidis: in vitro antibiotic susceptibilities and clinical outcomes. Ophthalmic Surg Lasers Imaging. 2007;38(6):446-51.

12. Park SS, Rabowsky J. Early postoperative endophthalmitis after pars plana Ahmed valve placement with persistent extraocular infection. Ophthalmic Surg Lasers Imaging. 2007;38(5):404-5.

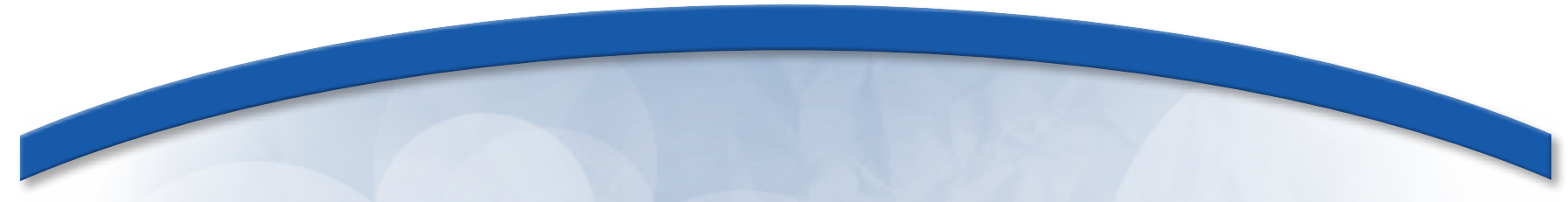

\section{1 - Simpósio Internacional de Glaucoma da UNICAMP}

20 e 21 de maio de 2016

\section{Hotel Maksoud Plaza}

São Paulo - SP

\section{Informações:}

Tel.: (11) 5575-0254

Site: www.simposioglaucomaunicamp.com.br E-mail: atendimento3@creativesolution.com.br

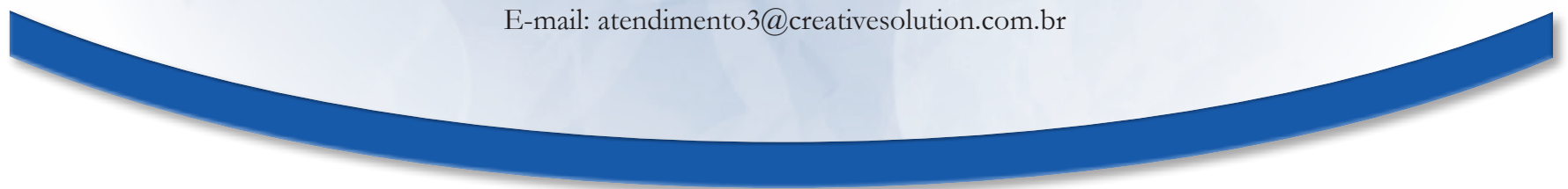

